\title{
PERLINDUNGAN HAK ASASI MANUSIA PENGUNGSI INTERNASIONAL
}

\author{
Ayub Torry Satriyo Kusumo \\ Fakultas Hukum Universitas Sebelas Maret \\ ayub_satriyo@yahoo.com
}

\begin{abstract}
Refugees are a group of people who were forced to leave the country because of very threatening fear. Fear is often due to natural disasters or conflict. In countries receiving refugees, they often experience inhumane treatment such as rape, assault, discrimination, repatriated by force, those lead to the violation of human rights. There has been regulation for human rights in refugee issues both internationally and regionally, for instance Convention related to Status of Refugee 1951 and The Protocol related to the Status of Refugee 1967. There are at least five basic rights of refugees, they are the right to be protected from returning to the country of origin forcibly (non refoulement), the right to seek asylum, the right to obtain equality and non-discrimination, the right to live and to be secured, as well as the right to return home.
\end{abstract}

Key words : International Convention on Refugees, Status of Refugee, Human Rights Protection

\begin{abstract}
Abstrak
Pengungsi adalah kelompok orang yang dipaksa untuk meninggalkan suatu negara karena takut yang sangat mengancam, dapat disebabkan oleh bencana alam atau konflik. Di negara-negara penerima, pengungsi sering mengalami perlakuan tidak manusiawi seperti perkosaan, penganiayaan, diskriminasi, dipulangkan secara paksa yang mengarah pada pelanggaran hak asasi manusia. Ada pihak-pihak yang telah menetapkan hak asasi manusia dalam masalah pengungsi baik internasional maupun regional, seperti Konvensi Status Pengungsi dari tahun 1951 dan Protokol yang berkaitan dengan Status Pengungsi 1967. Setidaknya ada lima hak dasar pengungsi, yaitu hak atas perlindungan dari kembali ke negara asal secara paksa (refoulement non), hak untuk mencari suaka, hak untuk mendapatkan kesetaraan dan non-diskriminasi, hak untuk hidup dan keamanan, serta hak untuk pulang.
\end{abstract}

Kata kunci : Konvensi Internasional tentang Pengungsi, Status Pengungsi, Perlindungan Hak Asasi Manusia

\section{A. Pendahuluan}

Pada prinsipnya perlindungan pengungsi merupakan tanggung jawab setiap negara (Sigit Riyanto, 2004 : 67). Pengungsi merupakan persoalan yang selalu timbul dalam setiap perkembangan manusia. Pengungsi dapat berawal dari rasa takut yang sangat mengancam keselamatan mereka (Achmad Romsan, 2003 : 3). Rasa takut tersebut dapat ditimbulkan oleh bencana alam atau karena bencana buatan manusia yang dalam hal ini konflik. Pada mulanya permasalahan pengungsi merupakan masalah domestik suatu negara, namun pada saat ini dengan perkembangan konsep Hak Asasi Manusia (HAM) isu pengungsi sudah menjadi permasalahan internasional (Erika Feller, 2001: 130).

Pada umumnya, pengungsian

Yustisia Vol.1 No.2 Mei - Agustus 2012 dilakukan karena terjadinya penindasan hak asasi pengungsi di negara mereka. Para pengungsi juga mencari tanah atau negara lain sebagai tempat kediaman barunya yang tentunya jauh dari penindasan hak asasi manusia. Pencarian negara baru oleh pengungsi tentu saja harus dianggap sebagai suatu hak asasi manusia (Soffa S.A, 2011 : 1). Konvensi mengenai Status Pengungsi tahun 1951 atau Konvensi Jenewa tentang status pengungsi adalah dasar hukum pengungsi internasional. James C. Hathway mendefinisikan International refugee law is designed only to provide a back-up source of protection to seriously at-risk persons. Its purpose is not to displace the primary rule that individuals should look to their state of nationality for protection, but simply to provide a safety

Perlindungan Hak Asasi Manusia...

169 
net in the event a state fails to meet its basic protective responsibilities. Dalam terjemahan bebas bahwa hukum pengungsi internasional ini dirancang hanya untuk menyediakan sumber pendukung bagi perlindungan untuk orang-orang yang benar-benar berisiko. Tujuan dibentuknya Hukum Pengungsi Internasional adalah bukan untuk menggantikan aturan utama, bahwa individu harus mencari perlindungan kepada negaranya, melainkan secara sederhana menyediakan jarring pengaman bilamana suatu negara gagal melakukan tanggung jawab perlindungan yang mendasar. (James C. Hathaway, 1999: 1) .

The Convention relating to the Status of Refugees atau Konvensi Jenewa 1951 tentang status pengungsi merupakan dasar hukum bagi pengungsi internasional. Definisi pengungsi menurut Pasal 1 Konvensi 1951 adalah "Refugee relates to a person who owing a well-founded fear of persecution for reasons of race, religion, nationality, membership of a particular social group or political opinion, is outside his country, and is unable or unwilling to avail himself of the protection of that country". Konvensi tersebut memberikan batasan status pengungsi internasional yaitu pengungsi yang tercatat sebelum 1 Januari 1951. Dikarenakan persoalan pengungsi meningkat antara tahun 1950 dan 1960, maka diperlukan cakupan yang lebih luas terkait pengungsi internasional. Sehingga disepakati Protokol tambahan terhadap pengungsi yaitu Protocol relating to the Status of Refugees atau Protokol New York 1967. Adapun Protokol 1967 tidak memberikan batasan peristiwa terkait pengungsi (Sri Setyaningsih Suwardi, 2004: 25).

Prinsip-prinsip hukum internasional di dalam konvensi internasional tentang perlindungan pengungsi pada hakikatnya berasal dan merupakan penegasan dari hukum kebiasaan internasional (International Customary Law), dengan implikasi hukum mengikat semua negara tanpa mempertimbangkan negara tersebut telah meratifikasi konvensi tersebut atau belum (Sigit Riyanto, 2004 : 68). Indonesia merupakan salah satu negara yang sampai saat ini belum meratifikasi instrumen hukum internasional tentang perlindungan pengungsi, baik itu Konvensi 1951 maupun Protokol 1967.
Dalam pemahaman positivisme hukum, Indonesia tidak mempunyai kewajiban menerima terkait pengungsi yang datang ke Indonesia. Hal tersebut dikarenakan Indonesia belum mempunyai aturan hukum nasional terkait perlindungan pengungsi internasional. Sementara itu kenyataannya tidak sedikit pengungsi atau pencari suaka yang masuk ke wilayah Indonesia untuk mencari perlindungan terhadap pemerintah Indonesia. Permasalahan internasional dapat terjadi karena pengungsi merupakan permasalahan lintas batas negara yang di dalamnya terkait dengan proses masuknya orang asing ke wilayah Indonesia. Permasalahan yang sangat rentan terdapat dalam pengungsi internasional adalah pelanggaran Hak Asasi Manusia. Hal tersebut sering terjadi karena sebagian besar pengungsi tidak membawa dokumen resmi secara lengkap (UNHCR, 2005 : 124).

Penanganan pengungsi berbeda antara pengungsi internasional dengan pengungsi nasonal. Dalam hal ini perlu dipertegas kualifikasi pengungsi internasional. Hal tersebut penting dilakukan karena antara pengungsi internasional dengan pengungsi nasional berbeda perlindungan dan penanganannya. Tulisan ini membahas permasalahan perlindungan Hak Asasi Manusia pengungsi internasional.

\section{B. Pengaturan Pengungsi Internasional}

Konvensi 1951 dan Protokol 1967 pada prinsipnya hampir sama. Ada tiga hal pokok yang merupakan isi konvensi tersebut, yaitu :

1. Pengertian dasar pengungsi.

Pengertian dasar Pengungsi diartikan dalam Konvensi 1951 dan Protokol 1967 penting diketahui sebab diperlukan untuk menetapkan status pengungsi seseorang (termasuk pengungsi atau bukan). Penetapan ini ditetapkan oleh negara tempat orang itu berada dan bekerja sama dengan United Nation High Commissioner for Refugee (UNHCR), yang menangani masalah pengungsi dari Perserikatan Bangsa Bangsa (PBB).

2. Status hukum Pengungsi, hak dan kewajiban pengungsi di negara tempat pengungsian (hak dan kewajiban berlaku di tempat pengungsian itu berada).

Perlindungan Hak Asasi Manusia... 
3. Implementasi (pelaksanaan) perjanjian, terutama menyangkut administrasi dan hubungan diplomatik. Di sini titik beratnya administrasi dan hubungan diplomatik. Di sisni titik beratnya ialah pada hal-hal yang menyangkut kerja sama dengan UNHCR. Dengan demikian, UNHCR dapat melakukan tugasnya sendiri dan melakukan tugas pengawasan, terutama terhadap negaranegara tempat pengungsi itu berada.

Di samping diatur dalam Konvensi 1951 dan Protokol 1967, Pengungsi internasional juga diatur dalam Organization of Africa Unity Convention dan Cartagena Declaration. Organization of African Unity (OAU) Convention 1969 mengatur masalahmasalah pengungsi di wilayah regional Afrika dan mempunyai kekuatan hukum mengikat (legally binding) bagi wilayah regional Afrika. Konvensi OAU mengatur lebih lanjut mengenai definisi pengungsi yaitu someone who left his country because of external aggression, occupation, foreign domination or events seriously disturbing public order in certain parts or the whole of his country of origin or nationality. Regulasi tersebut mempunyai implikasi hukum bahwa orang yang melarikan diri keluar negara karena kerusuhan sipil, kekerasan yang tersebar luas, dan peperangan berhak untuk mengklaim status pengungsi di wilayah negaranegara yang menjadi pihak konvensi tersebut tanpa memperhatikan apakah mereka mempunyai rasa takut akan terjadinya penindasan atau persekusi yang mendasar (Sigit Riyanto, 2004 : 73). Diputuskan bahwa kelompok tertentu individu yang takut akan penganiayaan karena status sipil atau politik dan yang melarikan diri negara mereka harus dianggap sebagai pengungsi dan diberikan serangkaian tertentu hak yang membedakan mereka dari orang asing lainnya (Michael Barutciski, 1998: 11) .

Seperti halnya Konvensi OAU,

Deklarasi Kartagena 1994 juga menunjang definisi Pengungsi di Konvensi 1951. “...because thaeir lives, safety or freedom have been threatened by generalised violence, foreign aggression, internal conflicts, massive violation of human rights or other circumtances which have seriously disturbed public order" (Sigit Riyanto, 2004 :74). Berdasarkan definisi tersebut di atas, secara umum pengungsi adalah orang yang terpaksa memutuskan hubungan dengan negara asalnya karena rasa takut yang berdasar dan mengalami penindasan (persecution). Rasa takut yang berdasar inilah yang membedakan pengungsi dengan jenis migran lainnya, seberat apapun situasinya, dan juga dari orang lain yang membutuhkan bantuan kemanusiaan. Dengan diaturnya pengungsi internasional, berarti perlindungan pengungsi telah mempunyai kekuatan hukum dalam hukum internasional.

\section{Macam-macam dan Jenis Pengungsi}

Latar belakang terjadinya pengungsi dapat dikelompokkan dalam dua jenis, yakni (Prasetyo Hadi Purwandoko, 1998 : $5)$.

1. Pengungsian karena bencana alam (Natural Disaster). Pengungsian ini pada prinsipnya masih dilindungi negaranya keluar untuk menyelamatkan jiwanya, dan orang-orang ini masih dapat minta tolong pada negara dari mana ia berasal.

2. Pengungsian karena bencana yang dibuat Manusia (Man Made Disaster). Pengungsian disini pada prinsipnya pengungsi keluar dari negaranya karena menghindari tuntutan (persekusi) dari negaranya. Biasannya pengungsi ini karena lasan politik terpaksa meninggalkan negaranya, orang-orang ini tidak lagi mendapat perlindungan dari pemerintah dimana ia berasal.

Dari dua jenis pengungsi di atas yang diatur oleh Hukum Internasional sebagai Refugee Law adalah jenis yang kedua, sedang pengungsi karena bencana alam itu tidak diatur dan dilindungi oleh Hukum Internasional. Ada suatu istilah pengungsi yang disebut (Statutory Refugees). Statutory Refugees adalah Pengungsi-pengungsi yang berasal dari suatu negara tertentu yang tidak mendapatkan perlindungan diplomatik dari negaranya (negara asalnya). Pengungsi yang dapat dikategorikan sebagai Statutory Refugees adalah mereka yang memenuhi 
persyaratan seperti yang disebut dalam perjanjian Internasional sebelum 1951 (Prasetyo Hadi Purwandoko, 1998 : 5).
Dalam bagan berikut ini akan tampak pembedaan pengungsi(Prasetyo Hadi Purwandoko, 1998 : 6).

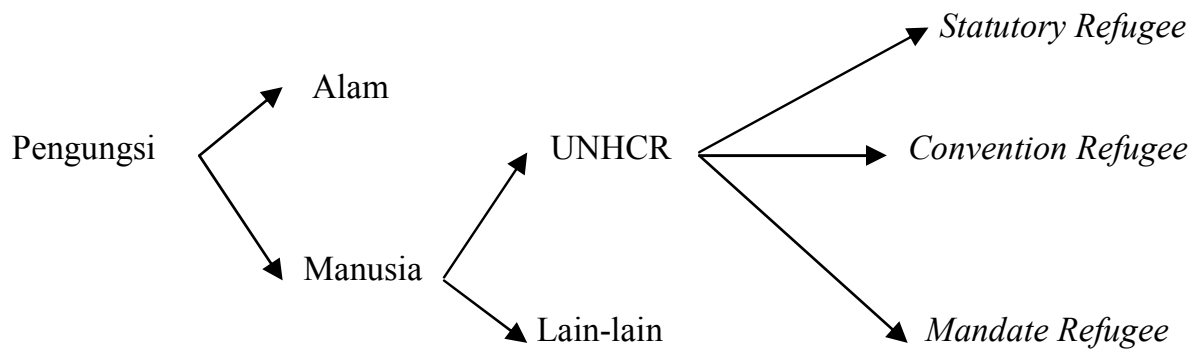

Penjelasan :

1. Statutory Refugee adalah status dari suatu pengungsi sesuai dengan persetujuan interansional sebelum tahun 1951.

2. Convention Refugee adalah stats pengungsi berdasarkan Konvensi 1951 dan Protokol 1967. Di sini pengungsi berada pada suatu negara pihak/peserta konvensi. Adapun pihak yang berwenang menetapkan status pengungsi adalah negara tempat pengungsian (negara dimana pengungsi itu berada) dengan kejasama dari negara tersebut dengan UNHCR, wujud kerja sama itu misalnya: dengan mengikut sertakan UNHCR dalam komisi yang menetapkan status pengungsi, bentuk kerjasama lainnya negara yang bersangkutan menyerahkan mandate sepenuhnya pada UNHCR untuk menetapkan apakah seseorang itu teramsuk pengungsi atau tidak

3. Mandate Refugee adalah menentukan status pengungsi bukan dari konvensi 1951 dan Protokol 1967 tapi berdasar mandate dari UNHCR. Di sini pengungsi berada pada negara yang bukan peserta konvensi atau bukan negara pihak. Yang berwenang menetapkan status pengungsi adalah UNHCR bukan negara tempat pengungsian. Mandate Refugee tidak ditetapkan

oleh negara tempat pengungsi dikarenakan negara tersebut bukan negara pihak dalam konvensi, sehingga tidak bisa melakukan tindakan hukum seperti dalam konvensi.

4. Pengungsi-pengungsi lain (sebab manusia):

Ada yang tidak dilindungi oleh UNHCR, misalnya : PLO, sebab PLO sudah diurus dan dilindungi badan PBB lain maka tidak termasuk lingkungan kekuasaan UNHCR.

Haryomataram membagi dua macam "Refugees, yaitu Human Rights Refugees dan Humanitarian Refugees (Andre Sujatmoko, 2011: 9-10).

1. Human Rights Refugees adalah mereka yang (terpaksa) meninggalkan negara atau kampung halaman mereka karena adanya "fear of being persecuted", yang disebabkan masalah ras, agama, kebangsaan atau keyakinan politik. Telah ada Konvensi dan Protokol yang mengatur Status dari Human Rights Refugees ini.

2. Humanitarian Refugess adalah mereka yang (terpaksa) meninggalkan negara atau kampung halaman mereka karena merasa tidak aman disebabkan karena ada konflik (bersenjata) yang berkecamuk dalam negara mereka. Mereka pada umumnya, di negara dimana mereka 
mengungsi, dianggap sebagai 'alien'Menurut Konvensi Geneva 1949, "alien" ini diperlakukan sebagai "protected persons". Dengan demikian mereka mendapat perlindungan seperti yang diatur, baik daam Konvensi Geneva 1949 (terutama Bag. IV), maupun dalam Protokol Tambahan I-1977.

$\begin{array}{r}\text { Dengan demikian dapat } \\ \text { dikatakan bahwa, } \\ \text { baik }\end{array}$
International Humanitarian Law
maupun International refugees
Law, mengatur masalah
"refugess".
Humanitarian Law memberikan
perlindungan
humanitaran refugees", sedang
International Refugees Law
mengatur "human rights
refugees".

\section{Ancaman Pelanggaran HAM Pengungsi Internasional}

Fakta menunjukkan bahwa jutaan anak-anak, pria dan wanita telah menderita akibat eksploitasi konflik etnis agama atau perang saudara. Jumlah ini dari tahun ke tahun meningkat secara tajam, Misalnya dalam kurun waktu 1992-1995 ada 180 juta pengungsi yang disebabkan bencana alam (natural disaster). Melihat hal ini Majelis Umum PBB telah mencanangkan periode 1990-2000 sebagai "the International Decade for Natural Disaster Reduction" (United Nations, 1995: 217-218).

Saat ini, perlindungan pengungsi masih menjadi alasan bagi keberadaan United Nations High Commissioner for Refugees (UNHCR). Sekitar 26 juta orang di dunia menjadi perhatian UNHCR. Mereka mencakup lebih dari 13.2 juta pengungsi, sedikitnya 4,7 juta orang yang terusir secara internal, 8,1 juta lainnya merupakan korban perang dan returnee. Jumlah paling besar berasal dari Afganistan (2,3 juta), Rwanda (1,7 juta), Bosnia dan Herzegovina (1,3 juta), Liberia (750.000), Irak (630.000), Somalia(466.000), Sudan (424.000), Eritrea (362.000), Angola (324.000), dan Sierra Leone (320.000) (UNHCR, 1998: 6).

Pembahasan pengungsi, tidak akan lepas dari HAM. Hal tersebut beralasan karena pengungsi merupakan manusia yang sangat rentan terhadap perlakuan yang tidak manusiawi baik di negara asal maupun di negara penerima. Kepergian pengungsi ke negara lain dikarenakan keadaan yang sangat terpaksa dan dimungkinkan tidak mempunyai dokumen. Perlakuan yang sering terjadi adalah penyiksaan, perkosaan, diskriminasi, dipulangkan secara paksa (refoulement). Erika Feller mengemukakan bahwa Refugee protection also embraces the safeguarding of basic human rights placed in particular jeopardy in refugee situations i.e. the right to life, liberty and security of person, the right to be free from torture and other cruel or degrading treatment, the right not be discriminated against, and the right of access to the basics necessary for survival i.e. food, shelter, medical assistance, as well as, at a later point, for self-sufficiency i.e. a livelihood, education, health care (Erika Feller, $2001: 3$ ).

Hal ini menjelaskan bahwa ancaman atas hak asasi memaksa orang untuk menyeberang ke negara lain untuk mencari perlindungan. Oleh karena itu, perlindungan hak asasi manusia di negara asal sangatlah penting untuk mencegah terjadinya gelombang pengungsi. "apabila kondisi negara asal telah berubah maka pengungsi dapat kembali lagi ke negara asal atau membangun komunitas mereka sendiri untuk menikmati hak asasi mereka" (UNHCR, $1998: 3$ ).

Perlindungan hak asasi manusia sangat essensial disuatu negara. Isu pelanggaran hak asasi manusia hampir selalu dipisahkan dari istilah pengungsi karena anggapan bahwaa pengungsi-lah yang dalam keadaan bersalah sehingga mereka mengungsikan dirinya. Kecenderungan saat ini adalah pengintegrasian antara hak asasi manusia, hukum humaniter dan hukum pengungsi, mengingat masalah pengungsi sekarang tumbuh sangat kompleks terkait jumlah, ukuran dan kompleksitas masalah pengungsi terbatas pada pendekatan pasca perang dunia II yang menepatkan masalah keselamatan dan kesejahteraan sebagai pertimbangan yang paling besar tanpa mempertimbangkan masalah negara penerima suaka apakah sudah melindungi pengungsi ataukah belum. Esensi hukum hak asasi manusia internasional mengatur kemanusiaan universal tanpa terikat atribut

Perlindungan Hak Asasi Manusia... 
ruang dan waktu tertentu (Agus Fadillah dalam Wagiman, 2012 : 28). Hak Asasi Manusia dalam konteks hukum pengungsi berhubungan dengan tiga hal yaitu perlindungan terhadap penduduk sipil dalam konflik bersenjata, perlindungan secara umum yang diberikan kepada penduduk sipil dalam keadaan biasa, dan perlindungan terhadap pengungsi baik Internal Displaced Persons (IDP's) maupun pengungsi lintas batas (Wagiman, 2012:28).

Masalah secara global saat ini mengenai masalah pengungsi tidak hanya masalah individu namun juga masalah hubungan internasional antara negara asal dengan negara penerima atau pemberi suaka, oleh karena itu diperlukan suatu hukum yang tidak hanya berkenaan dengan status hukum dan perlindungan pengungsi namun mencakup keseluruhan hukum yang mencakup solusi dan tanggung jawab kolektif semua negara. Hal ini diyakini dapat melindungi pengungsi terkait hak asasi manusia dan restrukturisasi rancangan Undang-undang tentang Pengungsi, selain itu juga dapat memberikan aksensi bagi negara miskin dalam menjamin hak asasi manusia terkait masalah pengungsi.

Terdapat tiga poin penting yang harus di perhatikan oleh suatu negara dalam melindungi pengungsi internasional (Karen Jacobsen, 2002 : 588).

1. Meningkatnya tuntutan pada birokrasi negara untuk mengelola populasi dan kebanyakan lembaga lemahnya negara dalam memberikan bantuan

2. Meningkatnya tuntutan pada aparatur negara untuk mengontrol dan mengelola sumber daya

3. Tuntutan meningkat pada aparat keamanan negara untuk mengontrol perbatasan dan ancaman keamanan yang ditimbulkan oleh masuknya pengungsi.

\section{E. Hak Asasi Manusia Pengungsi}

Hak Asasi Pengungsi meliputi sebagai berikut.

1. Hak Perlindungan Pengembalian ke Negara Asal secara Paksa (Non Refoulement)

Ketika seseorang atau beberapa orang melarikan diri dari negara asal, suatu negara harus memberikan perlindungan baginya atas pengembalian ke negara asalnya tersebut, hil ini diperlukan untuk menghindari pelanggaran hak asasi manusia lebih lanjut. Dengan alasan takut akan penganiayaan yang dapat membahayakan hidupnya, keamanan dan integritas. Komunitas internasional telah mengakui prinsip non-refoulement (The 1951 Refugee Convention (Art. 33(1)), UNHCR, Basic Legal Documents on Refugees (1999), 8-37; Article 3, United Nations Declaration on Territorial Asylum, Art. VIII of the Asian- African Legal Consultative Committee, Bangkok Principles, Art.II (3), OAU Convention 1969, Article 22(8), American Convention on Human Rights Convention, 1969). Kedua adalah menolak pengusiran dan pelarangan masuk ke suatu negara oleh pengungsi hal ini telah sesuai dengan konsep kembar dalam menjamin hak atas kemerdekaan, keadilan dan perdamaian dunia dibawah payung hak asasi manusia (Theofransus Litaay, 2003 : 2).

Dasar hukum bagi pengungsi atas non-refoulements adalah Pasal 9 Deklarasi Universal Declaration of Human Rights (UDHR), Article 5; UNHCR, Basic Legal Documents, pp.43-47; See also Convention Against Torture, Articles 2 and 6. Article 7 of the ICCPR ;1966. Malthus dalam menanggapi prinsip non-refoulement menggabungkan antara hukum internasional yang konvesional dan hukum lokal, dimana pemerintah membatasi secara sepihak untuk membatasi masuknya pengungsi ke negaranya dengan cara menangkap pengungsi di lautan atau menahan pihak penerbangan atau perkapalan yang membawa pengungsi, selain itu dengan membawa konsep baru "perlindungan sementara" dan "negara aman ketiga" (Malthus dalam James Hathaway, 1999: 9-11).

2. Hak Mencari Suaka

The State will bear joint responsibility for the fate of the asylumseeker as a matter of international law (Mary Crock, 2003 : 12). Setelah seseorang atau sekelompok orang terkena pelanggaran hak asasi manusia 
di negaranya maka yang paling dia cari adalah suaka. Suaka adalah suatu perlindungan yang diberikan oleh yurisdiksi suatu negara di wilayah negaranya bagi siapa yang datang untuk mencarinya (Article 1 of the Resolution adopted by the Institute of International Law in Sept. 1950, American Journal of International Law, vol. 50, Supplement ( 1951), p 15.). Suaka diperlukan tidak hanya untuk menjamin hak untuk hidup namun juga untuk mencegah terjadinya pelanggaran hak asasi manusia, oleh karena itu pemberian suaka untuk pengungsi korban pelanggaran hak asasi manusia merupakan aspek penting dalam perlindungan hak asasi manusia, karenanya pemberian suaka harus dipertimbangkan sebagai prinsip hukum internasional dalam piagam PBB. Pemberian suaka kepada pencari suaka yang sesuai dengan pasal 14 (DUHAM) tidak dapat dikatakan sebagai tindakan permusuhan oleh negara lain terutama negara asal pencari suaka (BS Chimni, 1998 : 18-22).

Suaka telah diatur dalam Pasal 14 ayat (1) Deklarasi Universal Hak Asasi Manusia (DUHAM) yaitu everyone has the right to seek and enjoy in other countries asylum from persecution. Prinsip yang mendasari UNHCR yaitu "apabila datang pencari suaka dalam skala besar, maka negara paling tidak memberikan perlindungan untuk sementara" (Michell Moussalli, $1982: 42$ ).

3. Hak Mendapatkan Kesetaraan dan nonDiskriminasi

Pengungsi mendapatkan hak untuk diperlakukan secara manusiawi oleh negara pemberi suaka. Sebagai aturan umum, hak dan kebebasan yang diakui hukum hak asasi manusia internasional dimiliki oleh semua orang termasuk pengungsi yang berhak untuk dihormati dan hak dasar sebagai manusia sebagaimana warga negara negara pemberi suaka (BS Chimni, 2003 : 15). Sangat penting perlingdungan hak asasi dan kemerdekaan pengungsi secara global dan regional, (ICCPR, Art. 2(1) ILM., vol. 6 (1967), p. 3687; ICESCR, Article 2 (2), ILM., vol.9 (1970), p.360, U.N. Charter, Arts. 1 (3), 13 (1) (b), 55 (c) and 76 (c); Universal Declaration of Human Rights, Art. 2; European Convention, Article 14213 UNTS 221; American Convention, Articles. 1 and 24; African Charter, Articles 2, 13, 18 (3)- ILM.,vol. 21 (1982),p. 58.), karena berada di negara asing pengungsi paling rentan terhadap diskriminasi. Tidak dapat dipungkiri pengungsi biasanya tidak membawa identitas maupun dokumen yang hal tersebut dapat menjadi masalah dengan otoritas negara pemberi suaka. Tidak jarang pula pengungsi diterima di negara penerima dengan kecurigaan dan tidak adanya kepastian hukum keberadaan mereka di negara penerima.

4. Hak Hidup dan Keamanan Pengungsi merupakan sekelompok manusia yang paling terancam di dunia. Sebagian hak-hak dasar mereka terancam pada saat proses mengungsi bahkan saat berada di negara asal. Pada awalnya mereka merasa putus asa karena kehilangan harta benda, keamanan, keluarga bahkan hidup mereka sendiri. Gil Loescher menjelaskan keadaan pengungsi sangat buruk bahkan lebih buruk dari ketika mereka berada di negara asal mereka, karena keterpaksaan untuk mengungsi (Gil Loescher, 1989 : 1-2). Seringkali pengungsi dipisahkan dari anggota keluarga mereka, mendapat ancaman, menjadi objek eksploitasi dan dihantui rasa takut akan dikembalikan secara paksa ke negara asalnya. Sebagian besar anak-anak yang hidup di kamp pengungsi tidak dapat hidup normal seperti anak-anak pada umumnya. Sering juga pengungsi beresiko mendapatkan kekerasan termasuk pembunuhan, pemerkosaan, genosida, penghilangan paksa .

Perempuan yang paling rentan menjadi korban kekerasan (UNHCR report in Refugees 1998 : 9). Mengingat ketentuan dari Undang-undang hak asasi manusia yang menjamin hak untuk hidup (Universal Declaration of Human Rights, Article 3; ICCPR, Article 6(1), American Declaration, Art. 1; American Convention, Art. 4 (1); European Convention, Art. 2 (1); African Charter, Article 4; CRC., Articles 6 (1) and 19.), dan perlindungan terhadap genosida 
(Article II, Genocide Convention, 1948.) yang merupakan bentuk pelanggaran yang serius terhadap hak untuk hidup. Karena hak untuk hidup adalah hak universal pengungsi harus dilindungi dari kesewenang-wenangan. Deklarasi Wina (1993) terkait diakuinya pelanggaran hak asasi manusia secara besar-besaran dalam bentuk genosida dan pemerkosaan secara sistematis yang menegaskan pelaku kejahatan semacam ini harus dihukum (Vienna Declaration, 1993, paragraph 28.). deklarasi ini menegaskan kepada semua negara agar melakukan penyelidkan apabila ditemukan bukti terhadap pelanggaran hak-hak pengungsi oleh siapapun. Sehubungan

dengan pemerkosaan dan kekerasan secara seksual mendorong semua negara untuk menerapkan undang-undang yang melindungi perempuan termasuk pengungsi perempuan.

5. Hak Kembali ke Negara Asal

Pengungsi perlu dijamin apabila ingin kembali ke negara asalnya secara suka rela. Selain itu pengungsi juga butuh perlindungan atas paksaan kembali ke negara asalnya. Hak asasi manusia mengatur hak individu untuk kembali ke negara asalnya (Universal Declaration, Article 13 (2); African Charter, Article 12 (2); CERD, Art. $5 d$ (ii). Art. 12 (4) of the ICCPR, Art. 22 (5) of the American Convention; Art. 3 (2) of the Fourth Protocol to the European Convention prohibits the deprivation of the right to enter the territory of the state of which a person is a national. The African Charter limits restrictions to those provided for by law for the protection of national security, law and order, public health or morality. Article 12;2 ). Dewan Keamanan PBB telah menegaskan "pengungsi dan orang terlantar berhak kembali ke negara asalnya" (U.N.S.C. Resolution 876 (1993) of 19 Oct, 1993 on the situation in Abkhazia on the right of Palestinians to return (Kathleen Lawland, 1996 : 532).

Komisi tentang pencegahan diskriminasi dan perlindungan kaum minoritas menegaskan "hak pengungsi dan orang terlantar untuk kembali ke negara asalnya dengan aman dengan pilihan mereka sendiri secara suka rela" (Sub-Commission resolution 1994/24, para 2 and 1995/13 para 2). Pengungsi memiliki hak untuk kembali ke negara asalnya dan menikmati kehidupannya. Dan negara penerima dapat mengembalikan pengungsi apabila telah diketahui di negara asalnya keadaannya telah kondusif dan pengungsi dikembalikan secara sukarela. UNHCR dan sejumlah organisasi lainnya yang bertanggungjawab atas pelaksanaan konvensi pengungsi 1951 konsisten menerima dan menolak hak manusia untuk kembali ke negara asalnya dengan repatriasi suka rela. Ghasan Arnaout mengatakan " dalam keadaan normal pencegahan lebih baik daripada mengobati maksudnya adalah pemulangan lebih bijak dilakukan secara suka rela (Ghasan Arnaout, 1996 $: 11)$.

Pemulangan tidak perlu dikhawatirkan karena memiliki syarat yakni keadaan negara asal yang kondusif. Oleh karena itu dalam memfasilitasi pemulangan pengungsi harus melibatka kedua negara dan UNHCR, sejauh syarat suka rela tidak perlu dikhawatirkan lagi sesuai Pasal V konvensi OAU 1969 (Asri Triaji, 2011 : 10).

\begin{tabular}{lrr}
\multicolumn{2}{c}{ Sub-komisi PBB } & untuk \\
pencegahan diskriminasi & dan \\
perlindungan kaum minoritas \\
menegaskan,"setiap orang
\end{tabular} tinggal dengan aman di negaranya sendiri"(Sub-Commission resolution 1994/94, para, 1, UN Doc. E/KN.4/ Sub.2/1994/56, 28 Oct. 1994 at 67. See also, resolution 1995/13, para 1, Report of the Sub-Commission on its Forty Seventh Session, Geneva 31 July-25 August 1995). Deklarasi Turku/abo tentang standar minimum kemanusiaan menyediakan pasal 7 ayat (1) "setiap orang berhak untuk tinggal dengan aman di negara mereka sendiri" sedang pasal 7 "tidak ada orang yang dapat dipaksa untuk meninggalkan negaranya sendiri". Hak ini sering disebut "hak untuk tidak jadi pengungsi". Komisaris Tinggi PBB untuk Pengungsi, Sadako Ogata mendesak masyarakat internasional untuk mencegah penyebab terciptanya gelombang pengungsi 
(Sadako Ogata, 1993:5). Terdapat legal frame work terhadap hukum pengungsi internasional (Wagiman, 2012 : 85) yaitu :

1. Treaties

These are the legally binding agreements among States that can either be open to alla countries (universal0 or specifically confined to a few States with shared interest (usually regional).

2. Customary International Law

This body of law consist of practices by States that have become so firmly established that they have became legally binding rules

3. General principle of Law

Where neither a treaty nor custom cover a particular issue, principle considered common to major legal system throughout the world can also be applied

4. Judicial Decisions

Made by States superior courts and the opinions of respected academics. These decisions and opinions assist in the interpretation of international law.

\section{F. Penutup}

1. Meskipun secara yuridis formal Indonesia belum meratifikasi ketentuan pengungsi internasional, Indonesia tetap berkewajiban melindungi pengungsi internasional, berdasarkan pada Internastional Customary Law bahwa atas dasar pemenuhan Hak Asasi Manusia, semua negara terikat (legally binding).

2. Pemahaman definisi dan kualifikasi pengungsi internasional dan pengungsi nasional secara komprehensif sangat dibutuhkan, karena berbeda dalam penegakan Hak Asasi Manusia dalam hal penentuan status pengungsi, kejelasan hak dan kewajiban pengungsi internasional dan pencari suaka. 


\section{DAFTAR PUSTAKA}

Achmad Romsan dkk. 2003. Pengantar Hukum Pengungsi Internasional. Hukum Internasional dan Prinsip-Prinsip Perlindungan Internasional. Jakarta : UNHCR.

Andre Sujatmoko. 2011. Hubungan antara Hukum Humaniter Internasional, Hukum Hak Asasi Manusia Internasional, dan Hukum Pengungsi Internasional. Makalah disampaikan dalam Short Course International Humanitarian Law. Yogyakarta : ICRC.

Anonim. 1995. United Nation Report about Refugee. New York : United Nation

1998. Information Paper. Jakarta : Regional office of UNHCR

1998. Human Rights and Refugee Protection. Jakarta : Regional Office of UNHCR.

1998. The Barriers are Going up Refugee. New York : Amnesty International.

----------. 1999. Basic Legal Documents on Refugees. Geneve : UNHCR.

--. 2004. Guidelines of International Refugee Protection, Teaching Materials. Geneve : UNHCR.

Asri Triaji dkk. 2011. Hubungan antara Pengungsi Internasional dengan Hak Asasi Manusia Internasional. Makalah disampaikan dalam perkuliahan Hukum Pengungsi Internasional. Surakarta : UNS.

BS Chimni. 1998. Refugees in International Law, The Geopolitics of Refugee Studies: A View from the South. Journal of Refugee Studies vol.11, no.4. New Delhi : Jawaharlal Nehru University. http://www.google.co.id/ \#hl=id\&output $=$ search\&sclient $=$ psyab\&q $=\mathrm{bs}+$ chimni\&oq $=\mathrm{bs}+$ chimni\&aq $=\mathrm{f} \& a q \mathrm{i}=\mathrm{g}-$

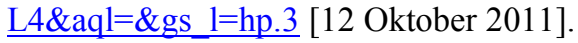

-----------. 2003. Refugees in International Law The Changing World Order, the Structural Role of Humanitarian NGOs, and the Protection of Displaced Persons and Migrants. Human Right Watch (HRW). Paper for the ICVA Conference on NGOs in a Changing World Order: Dilemmas and Challenges Geneva, 14-15 February 2003. http://www.icva.ch/doc00000936.html [12 Oktober 2011]

Erika Feller. 2001. The Evolution of the International Refugee Protection Regime. Journal Law and Policy. Geneve : UNHCR.

------------. 2001. International Refugee Protection 50 years on: The Protection Challenges of The Past, Present and Future. IRRC Journal. September Vol. 83 No 843. Geneve : UNHCR.

Ghasan Arnaout. 1996. Refugee Law Today. New York : United Nation.

Gil Loescher and Laila Monahan, (eds.) . 1989. Refugee Issues in International Relations. Refugees and International Relations journal. London : Oxford University.

James Hathaway. 1999. Crisis in International Law. Indian Journal of International Law vo1 39. Michigan : Michigan Law School.

1999. International Refugee Law: The Michigan Guidelines on the Internal Protection Alternative. First Colloquium on Challenges in International Refugee Law. Michigan : Michigan Law School. 
Kathleen Lawland. 1996. The Right to Return of Palestinians in International Law. International Journal of Refugee Law, vol. 8. http://www.forcedmigration.org/digitallibrary/journals/international-journal-of-refugee-law. [5 September 2011].

Karen Jacobsen. 2002. Can Refugees Benefit The State? Refugee resources and African Statebuilding. Journal of Modern African Studies. Cambridge : Cambridge University Press

Mary Crock. 2003. In the Wake of The Tampa: Conflicting Visions of International Refugee Law in the Management of Refugee Flows. Pacific Rim Law \& Policy Journal Association. Washington : University of Washington.

Michael Barutciski. 1998. Tensions between the Refugee Concept and the IDP Debate. Forced Migration Review : Norwegian Refugee Council.

Michell Moussalli. 1982. Who is a Refugee. Refugee Magazine. Geneve : UNHCR.

Prasetyo Hadi Purwandoko. 1998. Perlindungan Pengungsi (Refugee) menurut Hukum Internasional. Jurnal Yustisia. September-Oktober 1998. Surakarta : UNS.

Sadako Ogata. 1993. Statement at the Round Table Discussions on United Nations Human Rights Protection of Internally Displaced Persons. Nyon, Switzerland.

Sigit Riyanto. The Urgency of Refugee Legislation in Indonesia and The Present Obstacles. Indonesian Journal of International Law. 2 (1) October 2004. Jakarta : Universitas Indonesia.

Soffa Salsabila Alfafa. 2011. Peranan UNHCR dalam Menangani Masalah Perlindungan Pengungsi. Makalah. Surakarta : UNS.

Sri Setyaningsih Suwardi. 2004. Aspek Hukum Masalah Pengungsi Internasional. Jurnal Hukum Internasional. Vol 2 No. 1 Oktober 2004. Jakarta : Universitas Indonesia.

Theofransus Litaay. 2003. Penanganan Pengungsi menurut Hak Asasi Manusia. http://amalatu2005.multiply.com/journal/item/2/PENANGANAN PENGUNGSI DALAM P ERSPEKTIF HAK ASASI MANUSIA?\&show interstitial $=1 \& \mathrm{u}=\% 2$ Fjournal $\% 2$ Fitem. September 2011].

Wagiman. 2012. Hukum Pengungsi Internasional. Jakarta : Sinar Grafika. 